\title{
AVALIAÇÃO DO pH, TURBIDEZ E ANÁLISE MICROBIOLÓGICA DA ÁGUA DO CÓRREGO GUARÁ VELHO EM GUARAÍ, ESTADO DO TOCANTINS
}

\author{
Evaluation of ph, turbidity and microbiological analysis of the water of the Guara \\ Velho stream in Guaraí, Estado do Tocantins
}

Evaluación del ph, turbidez y análisis microbiológica del agua del córrego Guará Viejo en Guaraí, Estado del Tocantins

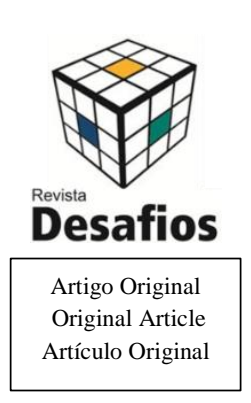

\section{Maria da Conceição Roberto ${ }^{1}$, Ana Paula Martins Guimarães ${ }^{2}$, Jhonys Lima Ribeiro ${ }^{3}$, Aluísio Vasconcelos de Carvalho ${ }^{4}$, Júlio César Ibiapina Neres ${ }^{5}$, Fernando Barnabé Cerqueira $^{6}$}

${ }^{1}$ Licenciada em Ciências Biológicas, Instituto Educacional Santa Catarina/Faculdade Guaraí (IESC/FAG), Guaraí, Tocantins, Brasil.

${ }^{2}$ Licenciada e Bacharel em Ciências Biológicas, Mestre em Ecologia de Ecótonos pela

Fundação Universidade Federal do Tocantins (UFT), Porto Nacional, Tocantins, Brasil,

Professora do Instituto Educacional Santa Catarina/Faculdade Guaraí (IESC/FAG), Guaraí,

Tocantins, Brasil.

${ }^{3}$ Bacharel em Administração de Empresas, Instituto Educacional Santa Catarina/Faculdade

Guaraí (IESC/FAG), Guaraí, Tocantins, Brasil.

${ }^{4}$ Licenciado em Ciências Biológicas, Mestre em Ciências do Ambiente, Professor do Instituto Educacional Santa Catarina/Faculdade Guaraí (IESC/FAG), Guaraí, Tocantins, Brasil.

${ }^{5}$ Licenciado em Ciências Biológica, Mestre em Ciências Ambientais e Saúde, Coordenador do

Curso de Ciências Biológicas doInstituto Educacional Santa Catarina/Faculdade Guaraî (IESC/FAG), Guaraí, Tocantins, Brasil.

${ }^{6}$ Agrônomo, Especialista em Docência no Ensino Superior, Mestre em Produção Vegetal, Doutor em Biotecnologia, Professor do Instituto Educacional Santa Catarina/Faculdade Guaraí (IESC/FAG), Guaraí, Tocantins, Brasil.

*Correspondência: Instituto Educacional Santa Catarina/Faculdade Guaraí. Avenida JK n ${ }^{\circ} 2541$ - Setor Universitário- CEP: 77700000 - Guaraí, TO - Brasil.e-mail biologa.apmg@gmail.com

\section{RESUMO}

A utilização da água pela sociedade é bastante ampla, abrangendo desde o uso pessoal da população, como também sua aplicação em atividades agrícolas e industriais. O presente trabalho teve por objetivo analisar a turbidez, presença de coliformes totais e de Escherichia coli na água do Córrego Guará Velho, Município de Guaraí-TO, utilizando o teste NMP com tubos múltiplos, seguindo as recomendações da portaria 357/2005. Foram recolhidos amostras de água em 5 pontos do Córrego e encaminhadas ao Laboratório de Águas do Município. Em todas as amostras foram identificados contaminação por coliformes totais e Escherichia coli, em alguns pontos a contaminação apresentou-se superior ao permitido pela portaria, favorecendo a inviabilidade desta água em ser consumida por animais e por seres humanos, assim como, sua utilização para outros fins. Neste trabalho, verificouse também que em alguns trechos do Córrego a turbidez ultrapassa o permitido de $100 \mathrm{NTU} / \mathrm{mL}$ de água. Diante dos resultados expressos por este trabalho, conclui-se que é necessário realizar projetos voltados a recuperação deste Córrego e de sensibilização da sociedade local a cerca da importância deste recurso para a população do Município e para o ambiente aquático, assim como, realizar novos trabalhos para atestar a qualidade da água deste córrego. 
Palavras-chave: Coliformes totais, Coliformes fecais e Escherichia coli.

\section{ABSTRACT}

The use of water by society is quite broad, ranging from the personal use of the population, as well as its application in agricultural and industrial activities. The present study had the objective of analyzing the turbidity, presence of total coliforms and Escherichia coli in Guarará Velho stream water, in the municipality of Guaraí-TO, using the NMP test with multiple tubes, following the recommendations of the ordinance 357/2005. Water samples were collected in 5 points of the stream and sent to the Water Laboratory of the Municipality. Contamination by total coliforms and Escherichia coli was identified in all samples, in some points the contamination was higher than allowed by the ordinance, favoring the non-viability of this water in being consumed by animals and by humans, as well as its use for others Purposes. In this work, it was also verified that in some sections of the Stream turbidity exceeds the allowed of $100 \mathrm{NTU} / \mathrm{mL}$ of water. In view of the results expressed by this work, it is concluded that it is necessary to carry out projects aimed at the recovery of this stream and sensitization of local society about the importance of this resource for the population of the Municipality and for the aquatic environment, as well as to carry out new works To attest to the water quality of this stream.

Keywords: Total coliforms, fecal coliforms and Escherichia coli.

\section{RESUMEN}

La utilización del agua por la sociedad es bastante amplia, abarcando desde el uso personal de la población, así como su aplicación en actividades agrícolas e industriales. Personal de la población, así como su aplicación en actividades agrícolas e industriales. El presente trabajo tuvo por objetivo analizar la turbidez, presencia de coliformes totales y de Escherichia coli en el agua del Corriente Guará Velho, Municipio de Guaraí-TO, utilizando la prueba NMP con tubos múltiples, siguiendo las recomendaciones de la ordenanza 357/2005. Se recogieron muestras de agua en 5 puntos del Corriente y se encaminaron al Laboratorio de Aguas del Municipio. En todas las muestras se identificó contaminación por coliformes totales y Escherichia coli, en algunos puntos la contaminación se presentó superior a la permitida por la portería, favoreciendo la inviabilidad de esta agua en ser consumida por animales y por seres humanos, así como su utilización para otros Los fines. En este trabajo, se verificó también que en algunos tramos del Corriente la turbidez sobrepasa lo permitido de $100 \mathrm{NTU} / \mathrm{mL}$ de agua. Ante los resultados expresados por este trabajo, se concluye que es necesario realizar proyectos dirigidos a la recuperación de este Corriente y de sensibilización de la sociedad local a cerca de la importancia de este recurso para la población del Municipio y para el ambiente acuático, así como, realizar nuevos trabajos Para atestiguar la calidad del agua de este arroyo.

Descriptores: Coliformes totales, Coliformes fecales y Escherichia coli.

\section{INTRODUÇÃO}

A utilização da água pela sociedade é bastante ampla, abrangendo desde o uso pessoal da população, como também sua aplicação em atividades agrícolas e industriais (ALVES et al., 2008). Rainho et al., (1999) afirmam que, na atualidade em torno de 1,4 bilhões de pessoas não consomem água potável no planeta, pois além deste recurso está distribuído pelo globo terrestre de forma desigual (GIATTI e CUTOLO, 2012), também está ficando cada dia mais escasso em diversas localidades devido aos impactos mediados por ações antrópicas.
Vendramel e Köhler (2002), afirmam que a disponibilidade de água em todo o planeta como um recurso hídrico infinito causa uma falsa sensação de ser um recurso natural inesgotável, e que a humanidade tem a tendência de ignorar o fato de que a maior parte da água da Terra $(95,1 \%)$ é salgada, portanto, inapropriada para o consumo humano e que somente $4,9 \%$ restantes é água doce e que poderia ser consumida pela humanidade, porém, deste quantitativo de água doce, somente $0,147 \%$ apresenta-se de forma potável, ou seja, apta a ser consumida pela sociedade Mundial. De acordo com Brasil (2011) não basta somente que esta água 
apresente aspectos físico/químicos adequados para ser considerada consumível, mas também aspectos microbiológicos, não devendo jamais, simbolizar riscos à saúde humana.

De acordo com a resolução 2914 do CONAMA de 2005, a água nunca deve ser consumida caso esteja fora dos limites estabelecidos por esta resolução. Portanto, toda água que estiver fora dos padrões preconizados são classificadas como poluídas e inadequadas para o consumo, podendo representar uma importante via de propagação de doenças de ciclo fecal-oral (BRASIL, 2005).

Segundo a Portaria $n^{\circ}$ 2914/2011, para que a água seja adequada e liberada para o consumo é necessários que os órgãos competentes pelo abastecimento de água de uma determinada localidade realizem testes pré-estabelecidos que comprovem sua viabilidade de consumo (BRASIL, 2011). Dentre os testes, estão inclusos aqueles que envolvem coliformes totais, coliformes termotolerantes e o Escherichia coli quantitativo (BRASIL, 2013) e outras variáveis que envolvam aspectos físico/químicos, e em especial pH e turbidez.

Os coliformes totais e coliformes termotolerantes, são bactérias que sobrevivem tanto na presença como na ausência de oxigênio (aeróbicas e anaeróbicas facultativas), que apresentam morfologia em forma de bastão, com parede celular do tipo gram-negativa, não apresentam esporos e são encontradas freqüentemente na microbiota intestinal do ser humano e em animais de sangue quente (BRASIL, 2013), sendo que Escherichia coli é a principal indicadora de contaminação fecal humana (BRASIL, 2013; BARROS et al., 2015).

A turbidez também está ligada a qualidade da água. O alto nível de turbidez está intimamente relacionado à existência de matérias orgânicas e argilas suspensas na água, em que, a agregação destes componentes dá origem a colóides que interferem na penetração da luz (APHA, 1995; FERREIRA et al., 2015). Outros parâmetros, como por exemplo, o tamanho e a geometria das partículas que podem interferir na coloração e dispersão da luz na água, presença de algas, plâncton, zinco, ferro, manganês e até mesmo areia (FELTRE, 1990), sendo que, para comprovar o alto índice de turbidez é necessário realizar testes quantitativos para liberar a água para o consumo humano.

Geralmente a inviabilidade da água doce por estes agentes é mediada pela deposição de dejetos humanos nos corpos hídricos de uma determinada localidade, como por exemplo: o lançamento de esgoto doméstico clandestinos, agrícola, resíduos químicos, resíduos sólidos e restos de matéria orgânica, que além de tornar a água inviável também contribuem para os elevados custos de tratamento (CARVALHO et al., 2000; VENDRAMEL e KÖHLER, 2002) e em alguns casos a dispersão de várias doenças.

Diante das informações citadas a cima, o presente trabalho tem por objetivo avaliar a turbidez, $\mathrm{pH}$, presença de coliformes totais e de Escherichia coli na água do córrego Guará Velho, localizado no Munícipio de Guaraí, Estado do Tocantins, utilizando o método de tubos múltiplos e quantificação em turbidímetro digital. A realização da presente pesquisa justifica-se pela ausência de estudos realizados no Município para atestar a qualidade das águas brutas que se encontram nas bacias hidrográficas do Município. 


\section{MATERIAIS E MÉTODOS}

O presente estudo foi realizado no Município de Guaraí (Figura 1), localizado no interior do Estado do Tocantins, situado na região Norte do Brasil, que faz parte da Mesorregião Ocidental do Tocantins e Microrregião de Miracema do Tocantins, sede da $6^{\mathrm{a}}$ Região Administrativa do Estado, com coordenadas geográfica de $08^{\circ} 50^{\prime} 44^{\prime \prime} \mathrm{S}$ e $48^{\circ} 30^{\prime} 36^{\prime \prime} \mathrm{W}$ e apresenta uma extensão territorial de $2.268 \mathrm{~km}^{2}$ (IBGE, 2016).

Figura 1. Mapa que demonstra a localização do Município de Guaraí no Estado do Tocantins onde se encontra o Córrego Guará Velho.

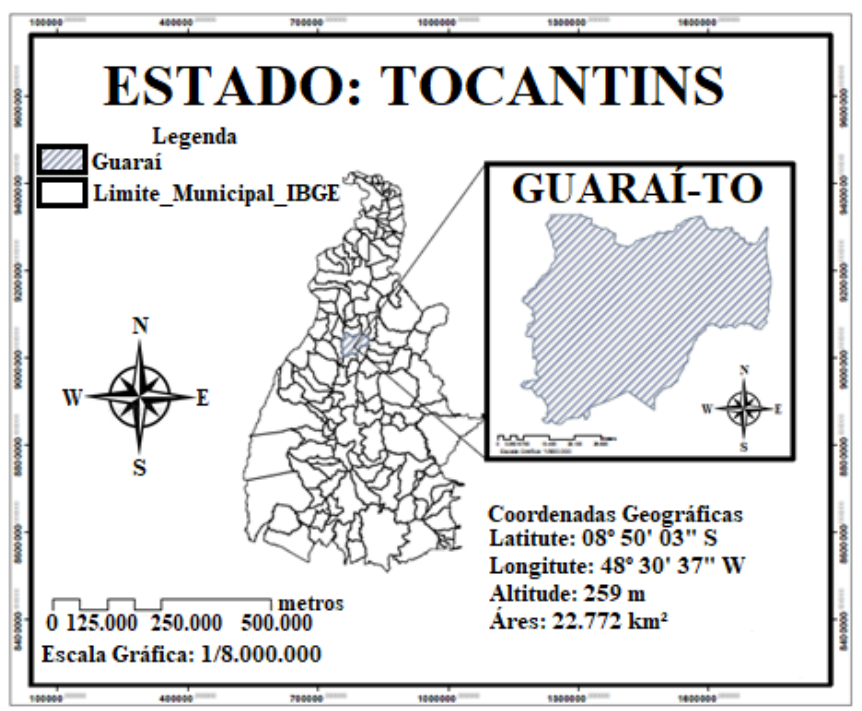

As coletas das amostras de água bruta foram realizadas no mês de Março de 2017, em 5 pontos no Córrego Guará Velho (Figura 2), em trechos que apresentam grande influência antrópica.

O primeiro ponto foi na nascente do Córrego, localizada dentro do Parque de Exposição Agropecuário de Guaraí (Tabela 1), para avaliar as condições da qualidade da nascente, comparando os resultados com aqueles obtidos ao longo do gradiente de distribuição da água em toda a área urbana da cidade.

O segundo ponto de estudado foi no canal do Córrego que corta a tradicional Praça do Povo, situada no Setor Pestana. O terceiro foi no canal que está situado na ponte da Rua 02, Setor Central do Município, onde se encontram várias residências dispostas exatamente às margens do canal do Córrego.

Figura 2. Mapa de Guaraí com destaque para o Córrego Guará Velho e os pontos de coleta.

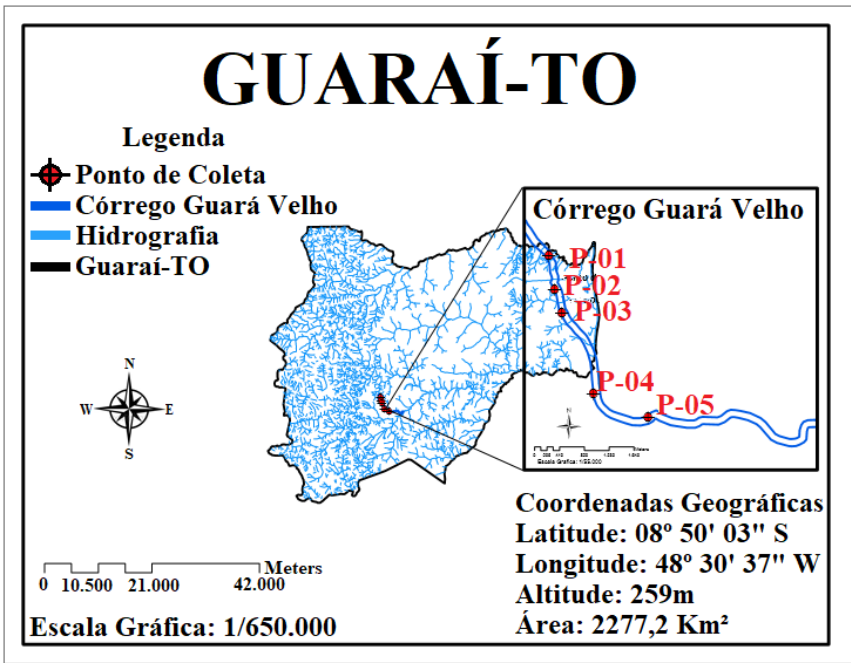

O penúltimo ponto escolhido foi numa área não canalizada do córrego, na ponte localizada na Rua Antônio Mendes Ribeiro, Setor Canaã. Este ponto foi escolhido, pois se trata do local em que o córrego sai do ambiente urbano e passa a ter a sua maior ocupação em um ambiente com pouca ou nenhuma urbanização.

Tabela 1. Coordenadas geográficas e altitude dos pontos de coleta da água para a análise de turbidez e microbiológica do Córrego Guará Velho.

\begin{tabular}{c|c|c|c}
\hline \multirow{2}{*}{ Ponto } & \multicolumn{2}{|c|}{ Coordenadas geográficas } & \multirow{2}{*}{ Altitude } \\
\cline { 2 - 3 } & Latitude & Longitude & \\
\hline $1^{\circ}$ & $8^{\circ} 49^{\prime} 20.65^{\prime \prime}$ & $48^{\circ} 30^{\prime} 36.86^{\prime}$ & 217 \\
$2^{\circ}$ & $8^{\circ} 49^{\prime} 39.00^{\prime \prime}$ & $48^{\circ} 30^{\prime} 33.77^{\prime \prime}$ & 227 \\
$3^{\circ}$ & $8^{\circ} 49^{\prime} 51.46^{\prime \prime}$ & $48^{\circ} 30^{\prime} 29.77^{\prime \prime}$ & 225 \\
$4^{\circ}$ & $8^{\circ} 50^{\prime} 34.85^{\prime \prime}$ & $48^{\circ} 30^{\prime} 12.33^{\prime \prime}$ & 217 \\
$5^{\circ}$ & $8^{\circ} 50^{\prime} 47.58^{\prime \prime}$ & $48^{\circ} 29^{\prime} 42.69^{\prime}$ & 225 \\
\hline
\end{tabular}


Neste ponto de coleta, pode ser observada a presença de uma vereda e uma menor quantidade de residências as suas margens, porém, alguns canos com perfurações manuais despejavam uma água de coloração verde escuro e odor fétido no solo fronteiriço ao córrego e em alguns casos até mesmo dentro do corpo hídrico, além do despejo de restos de material de construção e matéria orgânica em decomposição, inclusive de animais domésticos e restos de alimento.

O último ponto de coleta escolhido para a realização do presente trabalho foi no encontro das águas do Córrego Guará Velho com o Córrego Guarazinho em que também não consta canalização (Tabela 1). O encontro destes 2 córregos ocorre em um local de mata fechada e sem nenhum tipo de habitação antrópica. Porém foi observada a existência de uma grande quantidade de lixo doméstico despejado dentro do corpo hídrico.

De cada ponto foram coletados $100 \mathrm{~mL}$ de água em frascos esterilizados contendo $0,1 \mathrm{~mL}$ de tiossulfato de sódio a $10 \%$ da marca Uniglas, no intuito de neutralizar a ação do cloro residual oriundo da deposição de esgoto de cozinha dentro do Córrego de forma clandestina (Figura 3.A).

Figura 3. (A) Frasco de coleta para testes de turbidez da água. (B) Frasco de coleta para realizar as análises microbiológicas da água.

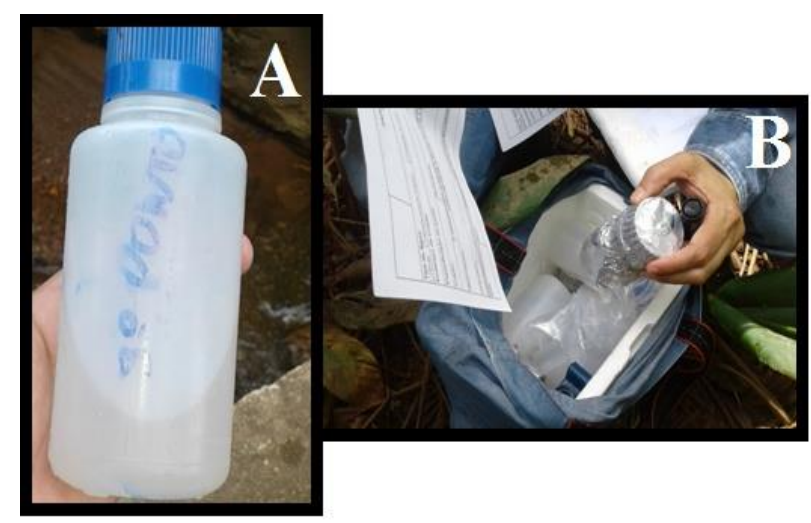

Para a realização da análise microbiológica, a água foi coletada seguindo as recomendações do Instituto Adolfo Lutz (2008) em frascos fisioquímicos para análise de turbidez de $100 \mathrm{~mL}$, ambos fornecidos pelo laboratório onde as amostras foram processadas. Ainda seguindo as recomendações do Instituto Adolfo Lutz (2008), conforme as amostras eram coletadas automaticamente iam sendo acondicionadas em uma caixa isotérmica (isopor) com gelo até o seu devido processamento (Figura 3.B) no laboratório.

o método utilizado para o processamento das amostras foi o método dos tubos múltiplos utilizandose o substrato cromogênico Colilert, recomendada pelo Standard Methods for the Examination of Water and Waste Water (APHA, 1997) sendo esta, a metodologia mais tradicional e recomendada para analisar e quantificar a presença de coliformes totais, coliformes termotolerantes e de E. coli através do NMP (número mais provável) dos grupos representantes destas bactérias em alimentos e água (ALVES et al., 2002).

Ainda seguindo as recomendações de Alves et al., (2002), esta metodologia está organizada em duas etapas (presuntiva e confirmativa), sendo indicado a realização da etapa confirmativa caso ocorra crescimento de coliformes totais na etapa presuntiva.

O substrato Colilert é formulado com a tecnologia própria para confirmação de bactérias pertencentes ao grupo de coliformes totais e de $E$. coli devido a reação de enzimas produzidas por bactérias do grupo coliformes com o meio de cultura, mudando a cor do meio e/ou tornando-o fluorescente em luz ultravioleta (BARROS et al., 2015). Os resultados expressos pelas bactérias do grupo coliformes totais possuem a habilidade de consumir o 
substrato contido no meio de cultura o-nitrofenil- $\beta$-Dgalactopiranosídeo a partir da síntese da uma enzima denominada $\beta$-galactosidase, conferindo a este meio de cultura uma coloração amarela e o consumo do meio de cultura contendo o substrato 4-metilumbeliferil- $\beta$-D-glucoronídeo por E. coli a partir da enzima $\beta$-glucuronidase confere um aspecto de coloração azul fluorescente (SCHUROFF et al., 2014).

Na primeira fase da análise, foram inoculados dentro de uma capela de fluxo laminar (marca Permution, com lâmpada UV de 365 NM, 6W de potência) $1 \mathrm{~mL}$ da amostra de cada ponto em água de diluição de $99 \%$, esterilizada na autoclave a $121^{\circ} \mathrm{C}$. Posteriormente adicionou-se o meio Colilert e distribuindo $10 \mathrm{~mL}$ em 10 tubos múltiplos estéreis para cada uma das amostras. Os 50 tubos foram incubados em estufa bacteriológica da marca Quimis, modelo $329 / 1$ por 24 horas a $35^{\circ} \mathrm{C}$ (ALVES et al, 2002).

Após a incubação, observou-se visualmente uma possível mudança de cor do meio de cultura nos tubos em luz ultravioleta (UV) para a leitura e interpretação dos resultados utilizando a tabela NMP (série de 10 tubos) proposta por Standard Methods (APHA, 1997). Os tubos que apresentaram cor amarela foram considerados positivos para coliformes totais.

Os tubos que expressaram coloração azul fluorescente foram contados e avaliados quanto aos resultados positivos para a presença de E. colli e o cálculo do NMP (Número Mais Provável) utilizandose da tabela Standard Methods (APHA, 1997).

Também foram realizados testes de turbidez na água do Córrego. A análise da turbidez em água doce atesta a sua qualidade e indica se esta se apresenta potável, sendo a turbidez um parâmetro que está intimamente ligada às propriedades ópticas que água apresenta em absorver ou refletir a luz (DI BERNARDO, 1993; CETESB, 2003), e ditam se a mesma está ou não própria para consumo humano ou por animais.

Os ensaios administrados nas amostras de água para obtenção dos resultados quanto o nível de turbidez foram realizados seguindo as recomendações APHA (1995), com adaptações, utilizando-se de um turbidímetro digital (NTU), cubetas de $25 \mathrm{~mm}$ e papel absorvente. Antes da realização das leituras o turbidímetro foi calibrado com água de calibragem livre de turbidez. Em seguida, as amostras de cada ponto foram colocadas nas cubetas e encaixadas no turbidímetro para a realização da leitura em NTU do nível de turbidez presente em cada amostra de água de acordo com o ponto de coleta. A sigla NTU (Nephelometric Turbidity Unit), advém do inglês que significa "Unidade Nefelométrica de Turbidez".

$\mathrm{O}$ pH da água foi determinado por meio de leitura em potenciômetro digital, e a MO e OD, seguindo a metodologia proposta por Winkler (APHA, 1995).

\section{RESULTADOS E DISCUSSÃO}

Neste estudo, os resultados mostram que, todas as variáveis trabalhadas, encontraram-se fora dos padrões exigidos pela portaria 2914/2011 (BRASIL, 2011), com apenas alguns pontos dentro dos padrões exigidos por esta resolução para turbidez e presença de E. coli na água, que permite sua utilização somente por animais. Em todos os pontos foram encontrados presença de coliformes totais e em nenhum dos pontos a água é indicada para o consumo por seres humanos em nenhuma hipótese, nem mesmo para a irrigação ou balneabilidade. 
Alguns fatores que podem estar contribuindo para este resultado no Córrego Guará Velho pode estar relacionado com a quantidade de esgotos clandestinos e deposição de lixo nas margens e no interior do Córrego, lançados pela população residente nas proximidades e até mesmo por moradores distantes, que utilizam este recurso natural como uma forma gratuita de descartes de materiais de construção e outros que não serão mais utilizados por estes.

De acordo com Goulart e Callisto (2003), a deposição materiais em corpos hídricos urbanos, geralmente está ligado à falta de saneamento básico adequado e a sensibilização de famílias de baixa renda que residem próximo a curso d'água, e que necessitam utilizar destes recursos para resolverem os seus problemas de saneamento, em que o resultado final é a depreciação dos ecossistemas aquáticos, que são transformados no passar do tempo em grandes depósitos de lixo e de esgotos sem nenhuma forma de tratamento podendo se tornar um potencial veículo de disseminação de inúmeras enfermidades por entre esta população.

Rodrigues et al., (2017) em seu trabalho intitulado "Desafios da saúde pública no Brasil: relação entre zoonoses e saneamento", afirmam que as questões sanitárias adequadas é um dos parâmetros mais importantes para manter a saúde de uma determinada população.

A Figura 4 mostra os resultados encontrados no Córrego quanto a turbidez. Os primeiros quatro pontos de coleta obtiveram resultados de níveis baixos em relação ao limite permitido pela resolução que é $100 \mathrm{NTU} / 100 \mathrm{~mL}$, variando entre 3,36 a 26,5 NTU/100 mL para a utilização por parte dos animais e sendo considerada completamente inviável para o consumo humano, tanto para irrigação como para balneabilidade, pois de acordo com Brasil (2011), a água destinada a este tipo de consumo não deve exceder 5 NTU/100 mL de turbidez.

No primeiro ponto (nascente do Córrego) a turbidez apresentou resultados de 3,36 NTU/100 mL, sendo o menor resultados expresso dentre os 5 pontos de coleta e estando dentro do estabelecido pela portaria 2914/2011 para o consumo humano (BRASIL, 2011). Este resultado pode ter intima relação com a localização do ponto, pois se trata de uma área (Parque de Exposição Agropecuário de Guaraí) restrita a população, a maioria não tem acesso a este local estudado.

Figura 4. Resultados em NTU quanto à turbidez da água coletada nos cinco pontos do Córrego Guará Velho, Município de Guaraí-TO.

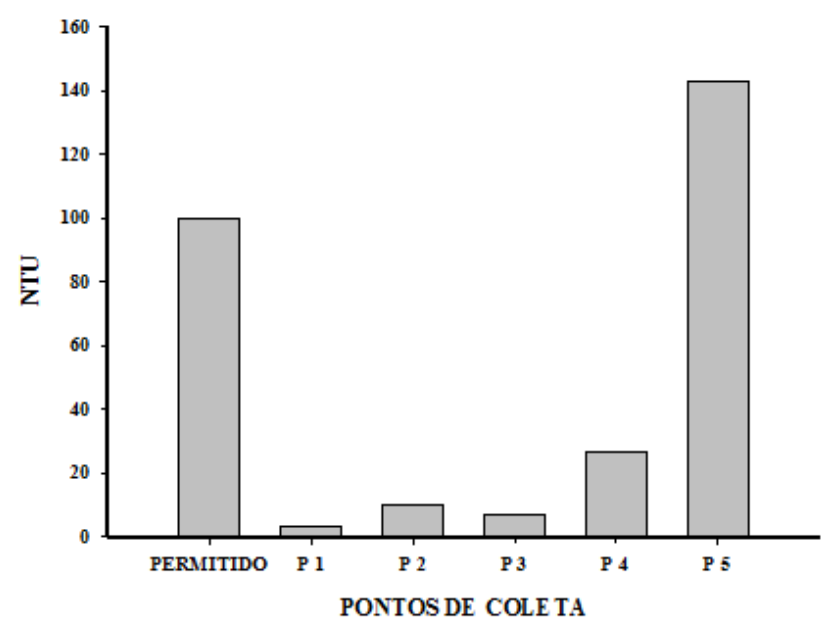

O resultado expresso no segundo ponto (Praça do Povo) foi de 9,77 NTU/100 mL, que se encontra dentro do permitido pela legislação para o consumo de animais, porém, não é permitido para o consumo humano em nenhuma hipótese, pois o resultado encontrado excedeu o limite estabelecido pela portaria 2914/2011 de $5 \mathrm{NTU} / 100 \mathrm{~mL}$. 
O terceiro ponto (localizado na ponte da Rua 2), obteve resultado inferior ao do segundo, com 6,58 NTU/100 mL, estando também dentro do permitido somente para animais. Os resultados apresentados por estes dois pontos, estando abaixo de 100 NTU/100 $\mathrm{mL}$ podem ter íntima relação com a canalização do Córrego, representando uma barreira limitante para a deposição de dejetos encontrados nas margens do Córrego e impedindo que estes dejetos possam cair dentro do curso d'água.

No penúltimo ponto (ponte da Rua Antônio Mendes Ribeiro, Setor Canaã) apresentando resultado de 26,5 NTU/100 mL, mesmo estando dentro do permitido pela portaria para animais. Esta parte do Córrego não possui canalização, o que pode justificar o aumento abrupto nos resultados de turbidez no quarto ponto de coleta.

No ultimo ponto (localizado no encontro do Córrego Guará Velho com o Córrego Guarazinho) expressou o maior resultado, ultrapassando o limite permitido, pela portaria, com resultado de 143,0 NTU/100 mL de água. O provável motivo para essa notável diferença seria a quantidade de sedimentos ao longo do Córrego.

A alta turbidez da água não a torna inviável somente para o consumo por parte do ser humano e dos animais, mas também, pode desencadear muitos problemas ao funcionamento do ecossistema natural. De acordo com Alves et al (2008), a água que apresenta uma alta turbidez pode reduzir a taxa fotossintética de plantas com raízes submersas e também das algas, interferindo diretamente na produção, impactando a comunidade de peixes e desequilibrando todo o ecossistema aquático. Além de todos estes problemas voltados a viabilidade da água, uma alta taxa de turbidez também pode torná-la imprópria para o uso doméstico, industrial e de recreação (CETESB, 2003).

Alves et al (2008), em seu trabalho de Avaliação da qualidade da água da bacia do rio Pirapó - Maringá, Estado do Paraná, por meio de parâmetros físicos, químicos e microbiológicos, encontrou resultados semelhantes aos do presente pesquisa, em que a concentração de turbidez, nos pontos estudados, variou de 10 a 180 NTU/100 mL, durante o período trabalhado. Siqueira et al. (2012), ao avaliarem a qualidade da água do rio Parauapebas, encontraram valores de turbidez dentro dos padrões da legislação, que oscilou em consequência do material em suspensão devido à entrada de materiais carregados para o interior do rio por meio da lixiviação. A mesma situação foi encontrada por Queiroz et al., (2010) em seu trabalho sobre "Influência do uso do solo na qualidade da água de uma microbacia hidrográfica rural", realizado no município de Cascavel-PR.

O teste realizado para constatar o $\mathrm{pH}$ da água coletada nos 5 pontos de estudo, apresentaram resultados muito próximos dentro de cada pontos. Ao longo do Córrego o pH variou entre 5.7 a 5.8, o que corresponde a um pH ácido. De acordo com Alves et al., (2008), as variações de pH tem íntima relação com a matéria orgânica, com os seres vivos, com a água e até mesmo com a matéria não viva encontrados em cada ambiente e, O’Neill (1995), declara que a acidez da água pode ter relação com o processo de decomposição de uma certa quantidade de matéria orgânica presente no corpo d'água.

Os testes para a presença de coliformes totais e de Escherichia coli também apresentaram resultados acima do permitido pela legislação. São testes importantes, pois se trata de um experimento que detecta bactérias patogênicas indicadoras de 
contaminação fecal de animais e/ou de humanos, encontradas preferencialmente em ambientes que receberam contaminação recente de esgotos não tratados, em águas naturais e solos que receberam contaminação por fezes (ALVES et al., 2008; BRASIL, 2013).

Em todas as amostras analisadas foram encontradas presença de coliformes totais, indicando contaminação recente por fezes de animais de sangue quente. Um trabalho realizado por Rodrigues et al., (2009), sobre a avaliação da qualidade das águas de duas áreas utilizadas para recreação do Rio Piracuama-SP, encontraram resultados parecidos aos resultados deste estudo, pois das 18 amostras estudas por estes pesquisadores 17 apresentaram contaminação por coliformes totais.

Quanto ao teste realizado para a presença de Escherichia coli os resultados obtidos demonstram que a água está em estado totalmente inadequado para a ingestão humana em todos os pontos onde ocorreu a coleta, considerando que o limite máximo estabelecido pela portaria 2914/2011 é a total ausência tanto de coliformes totais como para a presença de Escherichia coli por $\mathrm{mL}$ de água (BRASIL, 2011). Porém, em alguns pontos do Córrego esta água pode ser utilizada para balneabilidade (Tabela 2), com tanto que não seja ingerida em grandes quantidades (CONAMA, 2000).

Tabela 2. Classificação de água bruta para balneabilidade por categoria de qualidade, referentes a presença de coliformes fecais de acordo com as recomendações da resolução do CONAMA nº 274/2000.

\begin{tabular}{ccc}
\hline CLASSIFICAÇÃO & CATEGORIA & $\begin{array}{c}\boldsymbol{E} . \text { coli } \\
(\mathbf{N M P} / \mathbf{1 0 0}\end{array}$ \\
& & $\mathrm{MI})$ \\
\hline \multirow{2}{*}{ PRÓPRIA } & Excelente & 200 \\
& Muito boa & 400 \\
& Satisfatória & 800 \\
\hline IMPRÓPRIA & & +800 \\
\hline
\end{tabular}

(BARROS et al., 2015)

Por tanto, de acordo com a tabela 3 do presente estudo, os 3 primeiros pontos investigados encontravam-se apropriados para recreação, sem ingestão da água, enquanto que os dois últimos pontos estão completamente condenados para qualquer tipo de utilização deste recurso natural por seres humanos (CONAMA, 2000). 
Tabela 3. Presença de Escherichia coli quantitativa com série de 10 tubos. Valores permitidos para animais e seres humanos.

\begin{tabular}{lccccc}
\hline REF. & $\mathrm{P} 1$ & $\mathrm{P} 2$ & $\mathrm{P} 3$ & $\mathrm{P} 4$ & $\mathrm{P} 5$ \\
\hline V. P. & 000 & 000 & 000 & 000 & 000 \\
H. & $\mathrm{NMP} / 100$ & $\mathrm{NMP} / 100$ & $\mathrm{NMP} / 100$ & $\mathrm{NMP} / 100$ & $\mathrm{NMP} / 100$ \\
& $\mathrm{~mL}$ & $\mathrm{~mL}$ & $\mathrm{~mL}$ & $\mathrm{~mL}$ & $\mathrm{~mL}$ \\
V. P. & 1.000 & 1.000 & 1.000 & 1.000 & 1.000 \\
A. & $\mathrm{NMP} / 100$ & $\mathrm{NMP} / 100$ & $\mathrm{NMP} / 100$ & $\mathrm{NMP} / 100$ & $\mathrm{NMP} / 100$ \\
& $\mathrm{~mL}$ & $\mathrm{~mL}$ & $\mathrm{~mL}$ & $\mathrm{~mL}$ & $\mathrm{~mL}$ \\
RES & 161,0 & 230,0 & 230,0 & $2.320,0$ & $2.320,0$ \\
& $\mathrm{NMP} / 100$ & $\mathrm{NMP} / 100$ & $\mathrm{NMP} / 100$ & $\mathrm{NMP} / 100$ & $\mathrm{NMP} / 100$ \\
& $\mathrm{~mL}$ & $\mathrm{~mL}$ & $\mathrm{~mL}$ & $\mathrm{~mL}$ & $\mathrm{~mL}$ \\
\hline
\end{tabular}

*V.P.H. (valores permitidos para humanos); V.P.A. (valores permitidos para animais); RES (resultado).

Os valores de NMP de $E$. coli variaram entre 161,0 NMP/100 mL de água (ponto 1) a 2.320,0 NMP/100 mL (pontos 4 e 5) (Tabela 3).

Estes resultados também estão de acordo com aqueles encontrados por Cunha et al., (2004) que avaliaram a qualidade microbiológica utilizando a metodologia de tubos múltiplos de água de rios que passam por perímetros urbanos no baixo Amazonas e encontraram um número muito alto de contaminação fecal, que de acordo com afirmações dos autores, esta contaminação era originada pelos esgotos domésticos jogados nos rios em estudo. Alves et al., (2008), encontrou um número que variou entre 500 a 3.000 $\mathrm{NMP} / 100 \mathrm{~mL}$ de água diluída, também atingindo valores superiores aos estabelecidos pela portaria do CONAMA no 357/2005 (BRASIL, 2005). Rodrigues et al., (2009) também encontrou contaminação por $E$. coli na maioria das amostras coletadas Rio Piracuama-SP e estudadas por estes autores. O mesmo foi observado no trabalho realizado no Rio Almada, Sul da Bahia por Souza et. al., (2014).

Já os estudos realizados por Borges e Bertolin (2002) em seu trabalho sobre a qualidade microbiológica da água do Córrego São João, Porto Nacional-TO, em 85 amostras de água coletadas em 7 pontos do Córrego, foram encontrados vestígios da presença tanto de Coliformes totais, como de
Coliformes fecais em todos os pontos analisados. Para coliformes totais obtiveram valores médios de 126,0 NMP e de 286,0 NMP de Coliformes Fecais e Escherichia coli. Resultados estes, inferiores a aqueles encontrados neste trabalho tanto para coliformes totais como para a presença de E. coli, por tanto a água foi considerada apropriada para diversos tipos de uso, inclusive para o banho.

Já em relação ao uso da água pelos animais são liberados para uso os pontos 1, 2 e 3 , pois estavam de acordo com o exigido pela portaria 2914/2011 para este fim, apresentando resultados abaixo de $1.000 \mathrm{NMP} / 100 \mathrm{~mL}$ de água, 161, $230 \mathrm{e}$ 230 NMP/100 mL respectivamente. Em estudo realizado por Terra et al. (2010) com a água do Rio Jucu Braço Norte, no Espírito Santos obtiveram resultados diferentes daqueles encontrados no presente trabalho, pois todas variáveis limnológicas analisadas por estes autores encontram-se dentro dos padrões propostos pela legislação.

Os pontos 4 e 5 do presente trabalho apresentaram resultados que os colocam como inviáveis para ser utilizado por animais pois apresentaram um resultado igual a 2.320,0 NMP/100 $\mathrm{mL}$ de água para os dois pontos. Pinto (2011) afirma que, até mesmo a água destinada ao consumo animal, deve seguir as normas de segurança, pois se houver 
disseminação de micro-organismos patogênicos através desta água, poderá desencadear danos a saúde do animal e consequentemente interferir de forma negativa na produtividade, pois o consumo de água contaminada pode provocar diarreias e até mesmo abortamentos aos animais.

Quando são comparados os resultados de turbidez com os valores de NMP E. coli, o presente estudo demonstra uma forte relação entre estes dois parâmetros, pois os 2 pontos que apresentaram o maior índice de contaminação, também apresentaram maior turbidez (pontos 4 e 5). De acordo com Brasil (2011), águas que apresentam uma quantidade muito alta de turbidez são indicadoras de contaminação por micro-organismos, pois estes podem utilizar os sedimentos existentes na água para colonizar o seu interior e assim podem burlar qualquer tipo de procedimento de desinfecção da água para que esta possa ser consumida, podendo ser forte veículo de doenças pela falsa sensação de tratamento da água.

\section{CONCLUSÃO}

No presente estudo podem ser observados níveis muito altos de contaminação no Córrego Guará Velho, principalmente por esgoto doméstico clandestino e dejetos lançados as margens do Córrego pela população residente nas proximidades deste corpo hídrico. As análises de turbidez, pH, de coliformes totais e E. coli quantitativo evidenciam este tipo de contaminação, o que torna esta água completamente inapropriada para a ingestão humana, em alguns pontos até mesmo para balneabilidade e irrigação, e em alguns casos também para o consumo por parte dos animais, podendo trazer inúmeros problemas quanto a saúde dos organismos que por ventura consumirem a água deste Córrego.
Considerando os impactos ambientais e os futuros problemas voltados a falta de água potável para a humanidade e em alguns casos para o consumo de alguns animais, este trabalho identifica a importância da mobilização e sensibilização por parte de entidades educacionais e órgãos especializados na fiscalização desta natureza para esclarecer a população do Município de Guaraí, especialmente aqueles que residem as margens do Córrego da importância dos recursos hídricos para a sobrevivência dos seres humanos e dos outros organismos que habitam a biosfera, assim como, os problemas que podem ser acarretados pela perda deste recurso para a população de Guaraí.

Identifica-se também a necessidade de um planejamento por parte dos governantes e órgãos fiscalizadores do Município na tentativa de salvar este Córrego de sua completa morte, ou de pelo menos tentar minimizar os danos que estão sendo ocasionados neste ambiente, necessitando de uma fiscalização intensificada e a adoção de atitudes preconizadas pela legislação na punição dos casos omissos.

Todos os autores declararam não haver qualquer potencial conflito de interesses referente a este artigo.

\section{REFERÊNCIAS}

ALVES, N.C.; ODORIZZI, A.C.; GOULART, F.C. Análise microbiológica de águas minerais e de água potável de abastecimento, Marília, SP. Rev. de Saúde Pública, v. 36, n. 6, p.749-751, 2002.

ALVES, E. C.; SILVA, C. F. da.; COSSICH, E. S.; TAVARES, C. R. G.; FILHO, E. E. de S.; CARNIEL, A. Avaliação da qualidade da água da bacia do Rio Pirapó - Maringá, Estado do Paraná, por meio de parâmetros físicos, químicos $\mathrm{e}$ microbiológicos. Rev. Acta Sci. Technol, v. 30, n. 1, p. 39-48, 2008.

APHA, AMERICAN PUBLIC HEALTH ASSOCIATION. Standard methods for the 
examination of water and wastewater. 19 ed. New York: APHA, WWA, WPCR, p. 1268, 1995.

APHA, AMERICAN PUBLIC HEALTH ASSOCIATION. Standard methods for the examination of water and waster water. 20. ed. Washington-USA, 1997.

BARROS, D. J.; MARQUES, A. K.; MORAIS, P. B. Avaliação ambiental com base em indicador microbiológico de balneabilidade no município de Palmas-TO. Rev. J. Bioen. Food Sci, v. 2, n. 4, p. 172-177, 2015.

BORGES, K. P.; BERTOLIN, A O. Avaliação microbiológica da qualidade da água do Córrego São João, Porto Nacional-TO, Brasil. Rev. HOLOS, Environment, v. 2, n. 2, p. 174-184, 2002.

BRASIL. Resolução CONAMA n. ${ }^{\circ}$ 357, de 17 de março de 2005. Dispõe sobre a classificação dos corpos de água e diretrizes ambientais para o seu enquadramento, bem como estabelece as condições e padrões de lançamento de efluentes, e dá outras providências. Diário Oficial da República federativa do Brasil, Brasília, Seção 1, p. 58-63. 2005.

BRASIL, Portaria n. ${ }^{\circ}$ 2914, de 12 de dezembro de 2011. Estabelece os procedimentos e responsabilidades relativos ao controle e vigilância da qualidade da água para consumo humano e seu padrão de potabilidade, e dá outras providências. Diário Ofcial da União, Brasília, 12 dez., 2011.

BRASIL, Ministério da Saúde: Fundação Nacional de Saúde. Manual prático de análise de água. $4^{\text {a }}$ ed., 150 p, Funasa, 2013.

CARVALHO, A. R.; SCHLITTLER, F. H. M.; TORNISIELO, V. L. Relações da atividade agropecuária com parâmetros físicos químicos da água. Rev. Química Nova, v. n.5, 2000.

CETESB, Companhia de tecnologia de saneamento ambiental. Relatório de qualidade das águas interiores do Estado de São Paulo 2002/CETESB, p. 264 p. 2003.

CUNHA, A.C. da.; CUNHA, H. F. A.; JÚNIOR, A. C. P. B.; DANIEL, L. A.; SCHULZ, H. E. Qualidade microbiológica da água em rios de áreas urbanas e periurbanas no baixo Amazonas: o caso do Amapá. Eng. Rev. Sanit. Ambient, v. 9, n.4, p.322-328, 2004.

DI BERNARDO, L. Métodos e técnicas de tratamento de água. v. I e II. Associação Brasileira de Engenharia Ambiental e Sanitária - ABES, 481 p. 1993.
FELTRE, R. Fundamentos da Química, vol. Único, Ed. Moderna, São Paulo/SP - 1990.

FERREIRA, A. C.; ROCHA, L. C.; FIGUEIREDO, M. do A. Análise do índice de qualidade de água na bacia do Córrego do Rio Acima, São João DelRei/MG. Rev. Nacional de Gerenciamento de Cidades, v. 03, n. 15, p. 94-105, 2015.

GIATTI, L. L.; CUTOLO, S. A. Acesso à água para consumo humano e aspectos de saúde pública na Amazônia Legal. Rev. Ambiente \& Sociedade, v. 15, n 1, 93-109, 2012.

GOUlART, M. D. C.; CALlisto, M. Bioindicadores de qualidade de água como ferramenta em estudos de impacto ambiental. Rev. da FAPAM, v. 2, n. 1, 2003.

IBGE, Instituto Brasileiro de Geografia e Estatística. Censo Demográfico, 2015.

IBGE, Instituto Brasileiro de Geografia e Estatística. Censo demográfico, 2016.

INSTITUTO ADOLFO LUTZ. Métodos físicoquimicos para análise de alimentos. Secretaria de Estado da Saúde, Coordenadoria de Controle de Doenças, 4ª ed. p. 1020, 2008.

O'NEILL, P. Environmental chemistry. London: Champman and Hall, 1995.

PINTO, F.R. Avaliação Microbiológica da Água de Dessedentação Animal em Propriedades Rurais da Microbacia de Córrego Rico na Estação da Seca. Depto. Medicina Veterinária Preventiva e Reprodução Animal- Tese de Doutorado apresentada à Faculdade de Ciências Agrárias e Veterinárias Unesp, Câmpus de Jaboticabal, 2011.

QUEIROZ, M. M. F.; IOST, C.; GOMES, S. D.; VILAS BOAS, M. A. Influência do uso do solo na qualidade da água de uma microbacia hidrográfica rural. Rev. Verde de Agroecologia e desenvolvimento sustentável. Vol.5, n. 4, p. $200-$ $210,2010$.

RAINHO, J. M. Planeta água. Revista Educação, São Paulo, v. 26, n. 221, p. 48-64, 1999.

RODRIGUES, C. F. M.; RODRIGUES, V. S.; NERES, J. C. I.; GUIMARÃES, A. P. M.; NERES, L. L. F. G.; CARVALHO, A. V. Desafios da saúde pública no Brasil: relação entre zoonoses e saneamento. Scire Salutis, v.7, n.1, p.27-37, 2017.

RODRIGUES, J. R. D. D.; JORGE, A. O. C.; UENO, M. Avaliação da qualidade das águas de duas áreas 
utilizadas para recreação do Rio Piracuama-SP. Rev. Biociências, Unitau, v. 15, n. 2, p. 88-94, 2009.

SCHUROFF, P. A.; LIMA, N. R.; BURGOS, T. N. LOPES, A. M.; PELAYO, J.S. Qualidade microbiológica da água do Lago Igapó de LondrinaPR e caracterização genotípica de fatores de virulência associados a Escherichia coli enteropatogênica (EPEC) e E. Coli produtora de toxina Shiga (STEC). Semana: Ciências Biológicas e da Saúde, v.35, n.2, p.11-20, 2014.

SOUZA, J. R. DE.; MORAES, M. E. B. DE.; SONODA, S. L.; SANTOS, H. C. R. G. A Importância da Qualidade da Água e os seus Múltiplos Usos: Caso Rio Almada, Sul da Bahia, Brasil. REDE - Revista Eletrônica do Prodema, v.8, n.1, p. 26-45, 2014.

SIQUEIRA, G.W.; APRILE, F.; MIGUÉIS, A.M. Diagnóstico da qualidade da água do rio Parauapebas (Pará - Brasil). Rev. Acta Amazonica. v. 42, n. 3, p. $413-422,2012$.

TERRA, V.R.; PRETTE-SANTOS, R.; ALIPRANDI, R.B.; BARCELIS, F.F.; MARTINS, J.L.D.; AZEVEDO JR, R.R.; BARBIÉRI, R.S. Estudo limnológico visando a avaliação da qualidade das águas do rio Jucu Braço Norte, ES. Natureza On Line, v. 8, n. 1, p. 8-13, 2010.

VENDRAMEL, E.; KÖHLER, V. B. A história do abastecimento de água em Maringá, Estado do Paraná. Rev. Acta Scientiarum, v. 24, n. 1, p. 253260, 2002. 